\section{FedUni ResearchOnline \\ https://researchonline.federation.edu.au}

Copyright Notice

This is the published version of:

Hoang, Ha \& Le, Quynh \& Terry, Daniel \& Kilpatrick, Sue \& Stuart, J. (2013). Continuity of carer in the public hospital system in the eyes of rural women and maternity health providers in Tasmania, Australia. Universal Journal of Public Health. 1. 1-6.

Available online at: https://doi.org/10.13189/ujph.2013.010101

Copyright $\odot 2013$ Horizon Research Publishing. This is an open access article distributed under the terms of the Creative Commons Attribution License (CC BY 4.0)

(http://creativecommons.org/licenses/by/4.0/). The use, distribution or reproduction in other forums is permitted, provided the original author(s) or licensor are credited and that the original publication in this journal is cited, in accordance with accepted academic practice. No use, distribution or reproduction is permitted which does not comply with these terms. 


\title{
Continuity of Carer in the Public Hospital System in the Eyes of Rural Women and Maternity Health Providers in Tasmania, Australia
}

\author{
Ha Hoang ${ }^{1, *}$, Quynh Lế ${ }^{1}$, Daniel Terry ${ }^{1}$, Sue Kilpatrick $^{2}$, Jacqueline Stuart ${ }^{1}$ \\ ${ }^{1}$ Department of Rural Health, University of Tasmania, Locked Bag 1372, Launceston, Tasmania 7250, Australia \\ ${ }^{2}$ Centre for University Pathways and Partnerships, University of Tasmania, Locked Bag 1354, Launceston, Tasmania 7250, Australia \\ *Corresponding Author: Thi.Hoang@utas.edu.au
}

Copyright $(C 2013$ Horizon Research Publishing All rights reserved.

\begin{abstract}
This study investigates Tasmanian maternity health providers' and rural women's experiences and views of continuity of care in the public health system and the feasibility of this model is explored. Semi-structured interviews were conducted with 22 women who had childbirth experiences in six rural areas in Tasmania in the past five years. In addition 20 multidisciplinary maternity health providers currently employed by the health care system were also interviewed. Multidisciplinary maternity health providers and rural women believed that continuity of carer would help them build up relationship with each other and contribute to their satisfaction with care. However, both Tasmanian maternity health providers and rural consumers recognised the challenges of providing continuity of carer in the current public health system due to the constraints of human resources. Given the human resource constraints in the public hospital system, women would be happy with the quality of care provided by the team of health professionals.
\end{abstract}

Keywords Continuity of carer, continuity of care, quality of care, views, experiences

\section{Introduction}

Continuity of care within maternity care has been strongly recommended throughout Australia.[1] Continuity of care isa shared philosophy among a group of health care providers, regarding how care should be provided; or how a set guidelines and protocols should be adhered to.[2,3]This must not be confused with continuity of carerwhich is the provision of care by a known carer or a small group of caregivers throughout the childbirth experience.[4,5] As such, within the childbirth experience, it has been argued that continuity of carer enables women to develop a relationship with the same caregiver (or team of caregivers) throughout pregnancy, birth and the postnatal period.[6]

Models of continuity of midwifery care include team and caseload midwiferywhich have been recommended and implemented in Australia and other developed countries.Team midwifery refers to a small team of midwives who provide antenatal, intrapartum and postnatal care.[3] Caseload midwifery is a small group of midwives who take responsibility for the main provision of care for an agreed number of women.[7]Studies involving randomised controlled trials (RCTs) suggests that midwife-led care is associated with an increase in vaginal births and a decrease in analgesia during labour, episiotomy and instrumental vaginal delivery.[5] A recent Australian RCT study found an association between caseload midwifery and a reduced rate of caesarean sections.[8]

In addition, it has been suggested that continuity of carer by midwives is associated with increased levels of women's satisfaction.[3,9,10] Despite this, Green et al. [4] reviewed seven core comparative studies that used measures of maternal satisfaction and concluded that "there has been an emphasis in existing literature on continuity of carer but little attempt to assess continuity or quality of care".

Notwithstanding the success of many RCT studies and advocates of continuity of midwifery care models, these models of care require midwives to be flexible with working patterns and time on call.[11] Although midwives providing continuity of carer experienced increased autonomy and job satisfaction[12,13], they also faced higher levels of burnout[7,14], concern about being on call and the disruption of family and social life. [12,13] This paper aims to investigate Tasmanian maternity health providers' and rural women's experiences and views of model of continuity of carer and its feasibility in the public health system.

\section{Materials and Methods}

This paper was part of a larger research project identifying women's needs in rural areas of Tasmania, Australia and employed a mixed-methods approach [15] using a survey and semi-structured interviews. This paper reports the 
qualitative findings of the study. Ethics approval for the study was granted by the Tasmanian Social Sciences Human Research Ethics Network.

\subsection{Research Questions}

- What are views and experiences of Tasmanian maternity health providers and rural women of the model of continuity of carer?

- Is it possible to provide continuity of carer in the public health system in their views and experiences?

\subsection{Interviews with Women}

Interview women were recruited through participation in a mail out survey questionnaire sent to six purposefully selected rural sites in Tasmania. Survey participants were asked to indicate their willingness to participate in a semi structured interview on the returned survey form. The interviews were conducted using a list of open-ended questions concerning women's maternity care experiences in rural Tasmania. Some main questions asked were presented below.

- Were you cared for by one main carer (doctor and/or midwife) from pregnancy to birth?

- How important is it to have one carer who is responsible for care from pregnancy to birth?

- What do you think about continuity of care or carer?

Is it possible to provide that care for women in public hospital?Forty-eight women consented to be interviewed. Saturation was determined by a team of researchers and achieved after conducting 22 interviews. The selection criteria for interview participants included being a female over 18 years of age; having had childbirth experiences in the past five years; and living in rural areas of Tasmania at the time of giving birth.

\subsection{Interviews with Health Professionals}

The key managers of hospitals and health centers such as the Directors of Child and Family Services and maternity unit managers across Tasmania were contacted for their assistance to recruit health professionals. The selection criteria for the interviews were that the participants are maternity care providers and currently employed by the health system in Australia. Through referral from the managers, 28 health professionals were invited to participate in the study and 20 agreed to participate.

Both the woman and health professional participants were asked about their background information including their views and experiences concerning continuity of carer. The interviews lasted from 30 to 45 minutes and were audio recorded.

\subsection{Data Analysis}

The qualitative data gathered from health professionals and women were transcribed verbatim, checked, cleaned and combined for analysis. All data were analysed using thematic analysis which requires the researchers to constantly analyse and compare newly gathered information before going back to new participants.[16] QSR - NVivo version 9.0 software [17] was used to organise transcripts and codes. To ensure the reliability of the study, an independent researcher who conducts research in the same field reviewed the raw data of the interviews and independently coded four interviews of a random sample of data. The researchers and the independent judge discussed the coding until agreement was reached.

Selected characteristics of the interviewed women and health professionals are presented in Table 1 and 2 respectively.

Table 1. Characteristics of interview women

\begin{tabular}{|c|c|c|}
\hline Characteristics & $\begin{array}{l}\text { No. } \\
\text { participants } \\
\text { (N) } \\
\end{array}$ & $\begin{array}{l}\text { Percentage } \\
(\%)\end{array}$ \\
\hline \multicolumn{3}{|l|}{ Age group } \\
\hline $18-21$ years & - & - \\
\hline $22-30$ years & 4 & 18.2 \\
\hline $31-40$ years & 15 & 68.2 \\
\hline Over 40 years & 3 & 13.6 \\
\hline \multicolumn{3}{|l|}{ Education } \\
\hline $\begin{array}{l}\text { Primary } \\
\text { school }\end{array}$ & 5 & 22.7 \\
\hline $\begin{array}{l}\text { Secondary } \\
\text { school }\end{array}$ & 11 & 50.0 \\
\hline University & 6 & 27.3 \\
\hline \multicolumn{3}{|l|}{ Other } \\
\hline \multicolumn{3}{|l|}{$\begin{array}{l}\text { Language } \\
\text { spoken at } \\
\text { home }\end{array}$} \\
\hline English & 22 & 100.0 \\
\hline Other & - & - \\
\hline \multicolumn{3}{|l|}{$\begin{array}{l}\text { Aboriginal } \\
\text { and/or Torres } \\
\text { Strait Islander }\end{array}$} \\
\hline No & 20 & 90.9 \\
\hline Yes & 2 & 9.1 \\
\hline \multicolumn{3}{|l|}{$\begin{array}{ll}\begin{array}{l}\text { Most recent } \\
\text { baby }\end{array} \\
\end{array}$} \\
\hline $\begin{array}{l}\text { Less than a } \\
\text { year ago }\end{array}$ & 1 & 4.5 \\
\hline $\begin{array}{l}1 \text { to } 2 \text { years } \\
\text { ago }\end{array}$ & 8 & 36.4 \\
\hline $\begin{array}{l}\text { Over } 2 \text { to } 5 \\
\text { years ago }\end{array}$ & 13 & 59.1 \\
\hline
\end{tabular}


Table 2. Characteristics of health professionals

\begin{tabular}{|l|l|l|}
\hline Characteristics & $\begin{array}{l}\text { No. } \\
\text { participants } \\
(\mathrm{N})\end{array}$ & $\begin{array}{l}\text { Percentage } \\
(\%)\end{array}$ \\
\hline Profession & & 45.0 \\
\hline Midwife & 9 & 25.0 \\
\hline Obstetrician & 5 & 30.0 \\
\hline $\begin{array}{l}\text { Child health } \\
\text { nurse }\end{array}$ & 6 & 5.0 \\
\hline $\begin{array}{l}\text { Work } \\
\text { Experience }\end{array}$ & 1 & 15. \\
\hline $\begin{array}{l}\text { Less than 5 } \\
\text { years }\end{array}$ & 3 & 80.0 \\
\hline 6-10 years & 16 & \\
\hline over 10 years & $\begin{array}{l}\text { Current work } \\
\text { place }\end{array}$ & 55.0 \\
\hline Health centres & 9 & 55.0 \\
\hline Major hospital & 11 & \\
\hline
\end{tabular}

\section{Findings}

The findings were organised into six major themes: (i) feeling cared for, (ii) midwifery-woman relationship, (iii) consistent advice, (iv) risk, (v) practical in the public health system and (vi) quality of care. Several sub-themes were also identified.

\subsection{Feeling Cared For}

This theme explains the reasons why women want to be cared for by the same carer.

Ten out 22 women expressed their feelings of being comfortable for having a main caregiver who looks after them throughout the period of having a baby.

It makes you feel more confident about the impending birth as you feel more comfortable asking questions to someone who you are familiar with. (Woman 15)

For some women, having continuity of carer makes them feel they are 'genuinely cared for', and 'not just someone's job'. One woman spoke of the importance of having continuity of carer for rural women:

Paramount. Many Mums are away from their family and have very little support. This is a very intimate time in a new parents life that we should be ensuring that the experience is as comfortable for the Mum as possible. Not just taking pot luck on who will care for you because you are in the public system. (Woman 9)

\subsection{Midwife-woman Relationship}

Thirteen out of 22 women believed that having one carer is important because the woman and caregiver have a chance to build up a relationship with each other.

The Caesar was a good experience, partly due to the pre, during and post support of my private midwifewho I'd built enough relationship with to know that if she said 'Caesar', we were happy to go that way. (Woman 4)

This is confirmed by the health professionals interviewed.

I think continuity of care is important because there is a lot of care that you provide to women, but there is only one where rapport is built. (Midwife 6)

\subsection{Consistence Advice}

The analysis of the interviews with women and health professionals reveals that having different caregivers caused inconsistency in advice and care and inconvenience for women.

Some (four) women experienced inconsistent advice and care from having different health professionals during their care.

I was told off by one midwife for taking my antibiotics at the wrong time and when another midwife told me another thing. (Woman 2)

Not only were women aware of inconsistency in advice due to having many caregivers, so were the caregivers.

This time women see one doctor, next time they see another doctor and each says different things. (Obstetrician 2)

When women see many different health professionals, it is inconvenient for both, in that they are required to cover the same issues several times.

It would be lovely to have one person all the way through as we wouldn't have to cover the same ground all the time. (Woman 16)

\subsection{Risk}

Having the same caregiver during the course of care for women caused some concerns to the health professionals interviewed.

\subsubsection{Poor Decision Making}

Some (four) health professionals believed that continuity of carer should not be provided because of safety reasons.

Continuity of care is the best option but as a team is the 
only way it can work as people need holidays and with long labours and double shifts midwives get very tired and wrong decisions can be made. (Midwife 1)

Continuity in that sense is not possible in our current system and it should not be provided because it is unsafe. (Obstetrician 1)

\subsubsection{Risk of Burnout}

A midwife who worked in the hospital system which offers a team midwifery program commented on this model.

We do have a team midwifery program which offers a continuity of care. They see them antenatally and technically they are supposed to see them in labour and then follow up postnatally. That does not happen due to staffing; people need their leave or they are off sick or they need a day off so therefore with staffing they are not replaced. (Midwife 4)

This is echoed in the interviews with women:

I got to know all the midwives during pregnancy but when I was in labour I ended up with a stranger. (Woman 14)

\subsection{Practical in the Public Health System}

Although both maternity health care providers and women recognised the benefits of having continuity of carer, some health providers (seven) and women (five) were often skeptical about its possibility in the current health care system.

It is nice, but the system of several birthing midwives being available all the way through made it a bit like a lottery of who will be there on the day. Be better if you could choose, but difficult to make them available for a long birth. (Woman 1)

It is important to have one main carer who is responsible for your maternity care but probably very impractical. (Woman 7)

I don't think it is possible in the public medical system. It does not work and I can't see that will ever change because of the nature of the public hospital system. (Midwife 7)

Some health professional mentioned about caseload midwives but believed that this model of care was not practical.

They have been talking about bringing in caseload midwives as they do it in other countries. But I do not think across the board that we can have that mode of care. (Midwife 6)

\subsection{Quality of Care}

Nine out of 22 woman participants believed that is was not important to have continuity of carer. Those women would be happy with the quality of care regardless of who provided care. They described the quality of service that they would appreciate as 'supportive', 'understanding', 'helpful', 'excellent' and 'above standard'.

[Continuity of carer is] not that important. I was happy to see different midwives as they were all very professional and lovely. (Woman 10)

I didn't really mind who I saw, so long as they were an expert. (Woman 3)

One woman was happy with the team of caregivers because of their quality services provided.

I didn't have just the one carer and feel very lucky to have been part of the midwife program at the [Name of the major hospital in Tasmania]. Every midwife or doctor that I had contact with was very supportive, understanding, friendly and helpful. (Women 18)

This is also consistent with what the health professional described about the services.

We are ensuring that the person has seen the same group or the same practice where the information is shared and they are likely to meet the person once or twice during their labour. That's something we should be able to provide and can be done. (Obstetrician 1)

\section{Discussion}

The findings of this study revealed that both maternity care providers and women believed that continuity of carer helps them build a relationship with each other and would contribute to their satisfaction which is consisted with the literature. $[3,9,10]$ However, both maternity care providers and women interviewed viewed that continuity of carer may not be practical in the current public system due to the human resource constraints. The health professional participants stated that it is impractical for staff to be available for work 24 hours a day, 7 days a week to make continuity of carer possible. This is supported by the literature reporting that midwives providing continuity of care often came at a cost to their personal lives[12-14] and found it challenging and difficult to provide continuity of carer to women.[18]

Another important finding of this study is that many women tended to appreciate the quality of care regardless the number of carers. Although the interviewed women saw different health professionals, they were happy with 
consistent and professional care. Women described the care that they would be satisfied as 'supportive', 'understanding', 'helpful', 'excellent, 'professional', 'lovely' and 'above standard'. This is supported by the literature[19] which suggests women were more concerned with the quality of the care which they received from the team of caregivers and were usually happy to receive care from any member of the team. Furthermore, it has been surmised that women do not often value continuity for its own sake; rather women value what they expect to follow from continuity which is consistent care from someone whom they can trust.[4]Moreover, Freeman [12] conducted a critical review of the literature which suggests that the continuity of carer was not a clear predictor of women's satisfaction, and that the women did not focus on the model of care provided but instead on the content of the care provided.

The findings of this study should be interpreted with cautions due to the small sample size and some women and health professionals may not have experienced the model of continuity of care. This may affect their view on 'what is must be best'. It is acknowledged that the study is not representative for the views of all women and health professionals. However, it does provide insight into some of the challenges encountered and thoughts by women, particularly those in rural areas of Tasmania, concerning the desire for and practicalities to provide continuity of carer.

\section{Conclusions}

The strength of this study is that it has an inclusive sampling technique, which incorporates midwives, obstetrician and nurses. The findings indicate that both multidisciplinary maternity health providers and rural consumers recognised the impracticability of providing continuity of carer, particularly when rural maternity units are continuing to close, constraining women to seek antenatal, intra partum and postpartum care from a number of sources. Although continuity of carer is invaluable, women in rural areas have a propensity to be concerned with continuity of quality rather than continuity of carer. This provides practical implications for policy and health providers about the designs and provision of models of maternity services in Tasmania, particularly for women living rurally.

\section{Acknowledgements}

The first author was supported to undertake this research by an Australia Postgraduate Award Scholarship.

\section{REFERENCES}

[1] Department of Health and Ageing. Improving maternity services in Australia: Report of the Maternity Services Review: Australian Government Department of Health and Ageing; 2009.

[2] McLachlan H, Forster D, Yelland J, Rayner J, Lumley J. Is the organisation and structure of hospital postnatal care a barrier to quality care? Findings from a state-wide review in Victoria, Australia. Midwifery. 2008;24:358-70.

[3] Waldenström U, Brown S, McLachlan H, Forster D, Brennecke S. Does Team Midwife Care Increase Satisfaction with Antenatal, Intrapartum, and Postpartum Care? A Randomized Controlled Trial. Birth. 2000;27:156-67.

[4] Green J, Renfrew M, Curtis P. Continuity of carer: what matters to women? A review of the evidence. Midwifery. 2000;16:186-96.

[5] Hatem M, Sandall J, Devane D, Soltani H, Gates S. Midwife-led versus other models of care for childbearing women. Cochrane Database Syst Rev 2008. 2008;4.

[6] NSW Department of Health. Primary maternity services in Australia - A framework for implementation Sydney: Australian Health Ministers' Advisory Council, 2008.

[7] Andrews S, Brown L, Bowman L, Price L, Taylor R. Caseload midwifery: a review. Midwifery Matters. $2006 ; 108$

[8] McLachlan H, Forster D, Davey M, Farrell T, Gold L, Biro $\mathrm{M}$, et al. Effects of continuity of care by a primary midwife (caseload midwifery) on caesarean section rates in women of low obstetric risk: the COSMOS randomised controlled trial. BJOG: An International Journal of Obstetrics \& Gynaecology. 2012;119:1483-92.

[9] Biro M, Waldenstrom U, Brown S, Pannifex J. Satisfaction with team midwifery care for low and high-risk women: a randomized controlled trial. Birth. 2003;30:1-9.

[10] Rowley M, Hensley M, Brinsmead M, Wlodarczyk J. Continuity of care by a midwife team versus routine care during pregnancy and birth: a randomised trial. . Med J Aust 1995; 163:289-93.

[11] Sandall J. Occupational burnout in midwives: new ways of working and the relationship between organizational factors and psychological health and wellbeing. Risk Decision and Policy. 1998;3:213-32.

[12] Freeman L. Continuity of carer and partnership: a review of the literature. Women and Birth. 2006;19:39-44.

[13] Collins CT, Fereday J, Pincombe J, Oster C, Turnbull D. An evaluation of the satisfaction of midwives' working in midwifery group practice. Midwifery. 2010;26:435-41.

[14] Sandall J. Team midwifery and burnout in midwives in the UK: practical lessons from a national study. MIDIRS Midwifery Digest. 1999;9:147-52.

[15] Tashakkori A, Teddlie CE. Handbook of mixed methods in the social and behavioural science. Thousand Oak: CA: Sage; 2003.

[16] Strauss A, Corbin J. Basics of qualitative research: techniques and procedures for developing grounded theory. Newbury Park, CA: Sage; 1990.

[17] QRS International Pty Ltd. Nvivo 9. Melbourne QRS International Pty Ltd; 2011. 
[18] Forster D, Newton M, McLachlan H, Willis K. Exploring implementation and sustainability of models of care: can theory help? . BMC Public Health. 2011;11:1-10.
[19] Allen I, Dowling B, Williams S. A leading role for midwives? Evaluation of midwifery group practice development projects. Policy Studies Institute, 1997. 